\title{
What can direct marketing do for branding and bonding?
}

\author{
RECEIVED: 22 MAY, 2000 \\ Fiona Debling,* Leslie de Chernatony and Sue Middleton \\ *Marketing Department, Bristol Business School, University of the West of England, \\ Frenchay Campus, Coldbarbour Lane, Bristol BSI 6 IQY. \\ Tel: (0I I 7) 965626I x 3439; e-mail: Fiona.Debling@uwe.ac.uk
}

\begin{abstract}
This paper adds to knowledge about direct marketing by focusing on what direct marketing does for brand building or for 'bonding' with customers. This issue is important because direct mail alone accounted for as much as $£, 1,665 m$ or 11.6 per cent of total advertising expenditure in 1998 in the UK. This is more than the total outdoor, radio and cinema advertising spend. The paper explores the issues from a direct marketing (DM) agency and DM brand experts' perspective. It examines to what extent there has been a shift during the past ten years from using direct mail as a tactical sales tool, to a longerterm, strategic brand-building tool. Four roles for DM in brand building emerge. Underexploited roles for DM in tailoring 'brand relevance' to selected consumers and in acknowledging or developing the 'brand experience' of existing customers are reported.
\end{abstract}

\section{INTRODUCTION}

This paper first seeks to appreciate the extent to which practitioners consider direct marketing (DM) helps to build brands and to strengthen any brand-consumer relationship. The second part of the paper proposes a model for brand building through direct marketing. This topic is important because increased advertising expenditure is now apportioned to direct marketing, yet the implications for brand management of increasingly direct communications with the consumer, have not been widely discussed. An indicator of the growth in direct marketing is that direct mail expenditure, including production and postage, increased from $6930 \mathrm{~m}$ in 1990 to $\mathcal{E} 1,665 \mathrm{~m}$ in $1998 .{ }^{1}$ Hartley and Picton note that DM share of budget has increased. 'In a recent survey of 229 companies conducted by the Direct Mail Information Services (Reed, 1998a), more than half said that an increasing share of their marketing budget was taken by direct mail'.2 Direct marketing's perceived attraction for marketers lies in its accountability and it has been suggested, that 'direct marketing is a better use of funds than above-the-line advertising, ${ }^{3}$ This paper attempts to position direct marketing in relation to long-term brand building and it
Fiona Debling is research assistant in marketing at Bristol Business School where she teaches consumer behaviour.

Leslie de Chernatony is the Professor of Brand Marketing and Director of the Centre for Research into Brand

Management at the Birmingham University Business School.

\section{Sue Middleton} has been research consultant and marketing lecturer at Bristol Business School and has recently specialised in direct marketing research. 
debates whether greater consideration could be given to brand development before, during and after direct marketing campaigns.

\section{LITERATURE REVIEW}

\section{A holistic brand definition}

The stress in this study is on what direct marketing can offer to support long-term brand building, since competitive advantage, and hence customer loyalty, are inferred as outcomes of effective branding, from de Chernatony and $\mathrm{McDonald} \mathrm{s}^{4}$ definition of a successful brand:

'A successful brand is an identifiable product, service, person or place, augmented in such a way that the buyer or user perceives relevant, unique added values which match their needs most closely. Furthermore, its success results from being able to sustain these added values in the face of competition'.

\section{Brand building}

A basic framework for brand building in general is outlined briefly here, followed by a summary of literature relating brand building more specifically to direct marketing. Agres and Dubitsky recommend the analysis of brand building in terms of the strength or weakness of four 'pillars' ie i) differentiation; ii) relevance; iii) esteem; and iv) knowledge, based on Young and Rubicam's BrandAsset ${ }^{\circledR}$ Valuator project. Agres and Dubitsky maintain that most marketers believe that brand building takes place as a consequence of sales, so that the main objective of communications is selling. They argue: 'creative briefing documents should... [be asking, for example]: "Other than wanting you to buy [product/service], what was the main idea of the commercial you just saw?", 5

\section{Brand building and customer bonding in direct marketing}

This section will first review success factors for brand building, when direct marketing is seen as an extension of advertising. Secondly, the section will summarise literature on developing a closer customer-brand bond through direct marketing.

\section{$D M$ as brand-building tool}

Contrasting with the view that brand identity must be rooted in business strategy, ${ }^{6,7}$ DM practitioner literature indicates that direct marketing's raison d'être is seen as chiefly behavioural, but that there may be an attitudinal spin-off 'because direct marketing drives response, influencing behaviour is its fundamental reason for being. Influencing attitudes is a useful by-product of this process. ${ }^{8}$

According to Joachimsthaler and Aaker, ${ }^{9}$ although brand managers in Europe have found that traditional mass media have become costly and inefficient because of fragmentation and rising costs, few are using direct marketing as a primary brand-building tool: 
'most agencies' talents, incentives and inclinations still lead them to rely on mass-advertising as their primary brand-building device. Agencies rarely suggest that a client lead brand-building with alternative media'.

Joachimsthaler and Aaker, however, describe the case of Nestle's Casa Buitoni Club in the UK where experiences of the brand (important to the 'knowledge' brand-building pillar mentioned earlier) were created for the consumer, rather than just rational information, thereby introducing an emotional bond through DM.

Similarly, Goldfish credit card is quoted as an award-winning example of where brand building was not viewed as the sole preserve of abovethe-line marketing.

'Many above-the-line agencies continue to view integration as the literal migration of imagery and typography across media. Where Goldfish really scores, however, is in recognising the true value of a multi-media approach — with a brand, values and voice clearly and consistently communicated through a multitude of ideas across a variety of media.' ${ }^{10}$

DM's role in strengthening bonds with customers

'In the past, brand building has been conducted almost exclusively abovethe-line but now, when it comes to the development of brand loyalty, many are looking to direct marketing' states Fletcher. ${ }^{11}$ But she is also quick to raise doubts about direct marketing's abilities to strengthen the brand-consumer bond. Like Reed ${ }^{12}$ on direct response television (DRTV), she questions whether DM can really build brands 'because it does not offer any real insight into the emotional bond consumers make with brands.'

She goes on to state that most databases collect only transactional and behavioural details, mainly to identify heavy users and the most valuable top 20 per cent of customers, as advocated by the differential marketing approach. $^{13-15}$ In response to this criticism, the agency Ogilvy One, suggests that direct marketers could add four or five questions to customer questionnaires to identify whether the individual has a strong emotional link to the brand, thereby highlighting which customers are 'an emotional risk'. ${ }^{16}$ Pearson advocates customer questionnaires in DM but with a more positive objective, viz. 'to determine how willing customers are to form a deeper relationship with company or brand'. ${ }^{17}$ Gardiner and Quinton, ${ }^{18}$ in a business-to-business case, refer to McCorkell ${ }^{19}$ in underlining the importance of interaction with the customer and quote Kashani ${ }^{20}$ when stating: 'Building the brand by listening to customers' feedback from direct marketing should underpin the loyalty approach'. Questionnaires are also recommended to show continued interest in customers, under 'branding objectives for mail', at two of the 
six relationship stages in Stone and Gamble. $^{21}$

Meanwhile, Tapp notes that 'Direct marketing has not traditionally been used in order to build symbolic values... one customer value where direct marketers do make a difference is status. Companies such as American Express, BMW and Hilton Hotels use direct marketing as a way of building and maintaining a feeling of exclusivity and privilege to both recruit and keep customers. ${ }^{22}$ This very discreteness of direct mail can be viewed as a drawback because it has 'relatively little to contribute in terms of generating the shared meaning necessary for brand acceptance'. ${ }^{23}$ In order for direct marketing to add to the 'knowledge' pillar of brand strength, de Chernatony and McDonald recognised that 'In some instances this may involve targeting promotional activity to the user's peer group to ensure they recognise the symbolic messages being portrayed by the brand'. ${ }^{24}$

As a result of Rapp and Collins' idea of a 'loving company'25 carelines abound, from Nestle's dietician to Nintendo's helpline for children. ${ }^{26}$ Pearson also encourages financial companies to shift from 'hard sell' to interactive communications, such as offering advice or information on interactive disks and soliciting consumer feedback at all stages. ${ }^{27}$

\section{AIMS}

As a consequence of the literature review the authors felt there was little empirical research, or theory since Pearson, ${ }^{28}$ that focused specifically on direct marketing and its relationship with brand building and customer bonding. The aims of this paper are therefore threefold:

- to determine what factors, if any, might be encouraging a more strategic, brand-building role for direct marketing

- to ascertain from direct marketing practitioners whether direct marketing is, or should be, a brand-building tool

- to examine what role, or roles, direct marketing practitioners perceive direct marketing to play in supporting branding or in building consumer commitment to a brand.

\section{METHODOLOGY}

Qualitative data were felt to be more appropriate than quantitative in this study as more complex questions can be asked than in a questionnaire, with the benefits of probing for deeper insights. Hussey and Hussey also maintain that 'An interview may permit a higher degree of confidence in the replies than questionnaire responses'. ${ }^{29}$ Lee suggests depth of interview can overcome the problem of interviewees giving what they perceive to be a 'correct' answer. ${ }^{30}$ In order to minimise such interviewer bias, for instance an urge to overstate the case for brand strategy, interviewees were invited to discuss examples of DM campaigns and research. 
Fifteen semi-structured depth interviews, each lasting at least one hour, took place between January and May 1998. Interviewees were selected primarily for their expertise in brand building in direct marketing and, secondly, for their expertise with financial services direct marketing. Five out of nine judges of a brand-building category in the 1997 DMA/Royal Mail Direct Marketing Award were recruited for interview. The remaining interviewees were creative directors or planners in direct marketing agencies meeting the following requirements:

- one of the top 20 on a direct marketing agency league table from Marketing ${ }^{31}$ which were ranked by turnover

- from a direct marketing agency holding at least one or more financial services accounts.

While three DMA judges interviewed were senior client-marketers with direct marketing experience, including database and planning, two judges were also creative directors within the top 30 DM agency league table. ${ }^{32}$ Half of the top 20 DM agencies (or 12 of the top 30 DM agencies), were therefore represented. Interviews were mostly located in London but were also conducted in Bath, Surrey and Manchester.

Interviews were recorded for transcription and analysis at a later date. Two interviewers were used in order to complete interviewing within the given timescales. An interview guide was followed to ensure that research objectives were met and that the same issues were covered by both interviewers:

- direct marketing's role in developing the brand

- how can direct marketing be used to build brand loyalty

- what improvements, if any, could be made

- how important is customer interaction to developing brand loyalty?

Analysis included the three key phases of description (content analysis of the responses); analysis; 'noting and exploring themes and patterns and regularities',33,34 and interpretation.

The consumer financial services sector was chosen as a context first because it remains the largest category of consumer direct mail - 'insurance, credit cards and banks accounting for a third of the most recently sent items' ${ }^{35}$ Secondly, several studies find weak branding, and consumers who do not recognise many brands, within financial services. ${ }^{36-38}$ Meanwhile, 'Over the past few years, the financial services industry has seen increased levels of switching supplier across almost all product areas'. ${ }^{39}$

\section{FINDINGS}

\section{Direct marketing vs Direct mail}

It was the intention of the study that direct mail would be discussed as a separate marketing communications 
medium. Interviewees were consistent, however, in insisting that direct mail should not be treated in isolation and preferred to talk about 'direct marketing' and 'marketing campaigns' as a whole, rather than using the term 'direct mail'.

Direct marketing was defined by a number of interviewees as 'behavioural communications' (DM group), that is, communications that lead to a response or action of some kind:

'What we do is behaviour-driving communications'. (DM arm of a marketing communication (marcoms) group)

Some agencies see perceptions being changed, almost by default, as a byproduct of direct marketing.

'The difference between it [DM] and awareness advertising is that it changes customer behaviour as opposed to changing customer perception. It may change perception as well but I think it should change behaviour and you should be able to measure and judge that very, very finely.' (DM agency)

Only three out of the 15 interviewees held a contrasting view that, on some occasions, direct mail could be used purely for the purpose of shifting attitudes, or in Pearson's 'customer activating' sense:

'You should use your direct market- ing programme to talk to people sometimes when you're not selling them something, which is a very hard bullet for a lot of clients to bite, because they can't see any payback in that activity when viewed in isolation.' (DM agency)

One of the three 'heretical' DM interviewees mentioned a major High Street retailer who is experimenting with warm messages to customers.

\section{Factors encouraging a more strategic role for $\mathrm{DM}$}

A number of factors were described by interviewees as underlying a potential shift towards a more strategic, brand role for direct marketing. These factors can be summarised to include economic pressures, DM market forces and technological advances which, in combination, shift measurement of the effectiveness of DM from pure response rates to include conversion rates and retention.

\section{Economic pressures}

High media cost 'running at $12 \%$ year-on-year increase' (brand-building judge and chairman of DM agency), was flagged up as one reason for leveraging brand through other media. 'One of the driving forces is the sheer cost of above-the-line media, which are prohibitive for many brands.' (DM arm of marcoms group)

'The less brand TV you see because of [high] cost and [lack of] availability and because of [increas- 
ingly fragmented] viewing habits, the more all the other elements of the marketing mix become important.' (DM agency)

Heightened competition, arising around the time of the 1991 recession, meant clients learnt that three-tiered headlines such as:

" "Free quote, free pen, free call" might increase response, but the campaign was dead in six months with poor conversion rates and poor customer loyalty'. (DM agency)

'The [1991] recession, I think, has changed a lot of clients' minds and what used to be "below-the-line". (DM group)

DM market forces

Account planning was said to have moved from certain advertising agencies into leading direct marketing agencies, such as Evans Hunt Scott, in the late 1980s. Mailshots were no longer viewed in isolation from other media and communications. DM agencies began to carry out research among non-respondents to their direct mail campaigns.

'You could tell how perceptions of the brand had shifted dramatically in the right direction, even where they didn't buy the car.' (DM agency)

The entry of big brands into DM, and especially automotive brands such as Audi, VW and LandRover, are thought to have contributed to greater creativity in the treatment of brand within direct marketing.

'I think the thing that changed direct marketing creatively in the eighties was that automotive companies discovered direct marketing.' (DM agency)

'Now the big brands from all categories, from fmcg, manufacturing, financial, they all see direct marketing as a core part of their marketing.... and they realise it has a significant impact on the brand.' (DM agency)

'That started on Brand Response TV and I now think we are starting to see that in press and all sorts of things as well.' (DM agency)

Technological advances

'It's very difficult to point to any brand or service that has not been established by a consistent heavyweight terrestrial television investment. But it will change in the next three to five years with the advent of set-top boxes... That's when the real media fragmentation will start.' (brand-building judge and chairman of DM agency)

Finally, a few interviewees mentioned exciting developments in database marketing:

'I can tell you without being indiscreet, there are fantastic, un- 
believable, technologically driven communications coming up the back strait that will make "Friends and Family" [British Telecom campaign] look like kindergarten, because they've got the technology and they've put the infrastructure together, it's mind-blowing the depth they can get into in terms of one-to-one communication and tracking.' (brand-building judge and chairman of DM agency)

Others were anxious as to how close a relationship customers might want with brands in some sectors. There was a general feeling of unease about using data to their full extent and the impact this might have on consumers' fears about invasion of their privacy.

\section{Debating DM's brand-building role}

$D M$ is not the first media choice for launching a new brand

A minority of interviewees felt it might be possible, over a period of time, to launch a new brand through direct marketing.

'Well, I don't think you can do that [build a new brand] necessarily just through direct mail... but we've got a project on the go at the moment that I can't tell you about, but we are going to launch a new car without any, what you would call "above-the-line" advertising.' (DM group)

Most participants in the research stated categorically that direct mail would not be the best choice of medium for building a new brand from scratch. Moreover:

'I think if you are going to reposition a brand or switch it round to perhaps a different segment of the market, that switch has to have been started above-the-line'. (DM agency)

Reasons for direct mail not being seen as an ideal medium for launching a new brand, or for brand repositioning, varied from being able to achieve greater emotion, impact, humour and three-dimensionality through television, to direct mail's perceived unpopularity, especially among consumers within the financial services sector:

'The medium influences the takeout of the message. If people have a low perceived-value of a medium, it's more of an uphill struggle to make it a broadly positive experience'. (DM agency)

Additionally, one interviewee echoed the literature ${ }^{40}$ by stating that:

'Direct mail is not so potent in creating that aura that this is a product that is universally accepted to be cool, stylish and fashionable'. (DM agency)

'On-brand' work increases response Nine of the 15 interviewees said they believe direct marketing is becoming 
more strategic and some added that 'on-brand' work in direct marketing increases response in addition to reinforcing brand values. Moreover, some agencies with this view could quote examples of clients measuring shifts in consumer brand attitudes, in addition to counting responses.

'Basically you will be measuring ... what it influenced in terms of any perception of what [store] is doing. Did it influence your feeling of loyalty to the brand? That's a regular process we go through. Quite apart from measuring response.' (DM agency)

Most interviewees saw brand building in direct marketing as supporting a broader media mix.

There was a strong degree of scepticism on the part of six interviewees as to how far direct marketing has altered from tactical sales promotion towards strategic brand development.

'Often large brands just use it as a tactic to gain sample in your trial, but not as an overall strategy for awareness, for brand building.' (brand-building judge)

Some interviewees felt that brand building was important in their agency, but that other DM agencies have a superficial understanding of brand:

'A DM agency generally has response, not brand, as its heartbeat. All agencies say "we are very strategic", all agencies talk about brand. Maybe one of the crucial things is how many of them have been employed as brand consultants and actually defined their clients' brand?' (integrated agency)

'I think to date a lot of lip service has been paid to it. But nothing has actually happened ... so depending on senior management's view; you can't commit a company which is trying to keep shareholders happy.' (brand-building judge)

Among the sceptics, however, was a feeling that direct marketing should do more for brand, but that response alone is often all that is measured:

'What we should be trying to do is say, "should we also measure how it adds to the brand experience or the whole brand values?" That's what we should be doing.' (DM arm of marcoms group)

One agency stated that increasing media fragmentation means that tracking individual transactions from a campaign and tracing the perceptual effects of direct marketing can be complex and that the latter is being neglected:

'When clients can measure the transactional value or percentage response of a communication, which they can do more easily with direct mail than with advertising, there is a huge danger that they neglect the hidden value of 
communication, the long-term effects, attitude. It's harder to put the emotional values on a spreadsheet.' (DM agency)

\section{Four roles for DM in brand development}

Four brand development roles for direct marketing could be discerned: sales assistant; brand ambassador; brand hostess; and a 'listener', interactive, or partnership role called the brand researcher role. A short description of each role follows.

\section{Sales assistant role}

Even strong advocates of brand development through direct marketing are united in agreeing that:

'Quite clearly a major component of direct marketing is direct selling'. (DM agency)

Consistent branding in mailings is said to help trigger sales, just as brand packaging on the supermarket shelf triggers purchase.

'One of the functions of brands is to help to trigger the purchase as well as to help you to charge a premium price.' (DM agency)

Consumer recognition of the branding is seen as an essential part of the selling process via direct mail:

'A basic element of branding is simply familiarity'. (brand-building judge)
'You need some cover when your direct marketing hits the doormat, so that at least people are familiar to some extent with who you are.' (DM agency)

Two interviewees went further, explaining that their research has shown that 'on-brand' direct mail, that recognises what is happening with the advertising, can gain higher responses than 'off-brand' mailings:

'I've never believed there is a conflict. And what you do find, in fact, is that if you produce work that is off-brand, it doesn't work as well; it doesn't actually pull as much response.' (DM agency)

Brand ambassador role

DM, according to most interviewees, bears some responsibility, as a brand ambassador, for differentiating the brand from the competition, and for reinforcing or elaborating brand values. An example given was:

'The Royal Society for the Protection of Birds ensure that any direct marketing communication, notwithstanding the immediate commercial objectives of the campaign, also reinforces three particular brand values they believe they represent'. (brand-building judge)

'Direct mail is ideal for transactions and at the same time making that brand come alive or refreshing the 
view of the brand, making it more relevant.' (DM agency)

One interviewee recommended a separate programme to reinforce or upgrade what people think they have just bought into:

'Basically what I'm saying is you've only done half the job if you've got everybody in but you haven't then consolidated.' (DM agency)

Brand values need to be distinct and differentiated from competitors so that the brand image can be tailored to fit the targets:

'Any brand and its associated values does not exist in isolation.... There needs to be an opportunity for creating brand distinction. There needs to be some idea why you are better than everybody else.' (brandbuilding judge)

One of the major drawbacks of financial services branding, as perceived by those interviewed, is that they forget that their brand values are being compared, by consumers, with the competition.

Some interviewees, however, commented on a deeper-rooted marketing problem found across all sectors: the lack of distinct brand identities for DM agencies to communicate:

'Yes, bringing brand values to life. And that in itself can be a bit of a job, because most company's brand values are a list of great statements: accessibility, intelligence, innovations. The same old words come up again. It's only a few brands like Virgin or Orange, Tango or Heinz that have something distinctive.' (DM agency)

Brand hostess role

The DM brand hostess role is a dual role.

First, it provides an enjoyable experience appropriate to the brand. Interviewees felt that in direct mail, especially in financial services, where mailers can be covered in APR rates, brands need to try harder to be entertaining, giving the customer

'at least...a pleasant experience'. (brand-building judge/DM agency)

As if working in a hotel, they need to show some recognition of who their customers are, acknowledging customers' preferences, not approaching them 50 times with the same question.

'Why shouldn't we hate these grubby mailings? I think that advertising, design on TV, has reached a certain standard. These people [consumers] now know that companies out there want to entertain them and want to have an intelligent dialogue with them.' (brand-building judge/DM agency)

The second part of its role is to acknowledge the customer, or perhaps offer preferential or exclusive treatment (luxury brands). Key success 
criteria for building brand loyalty, and indeed for increasing the rate of cross-sales, through DM, were seen as relevance and customer recognition.

'There are all sorts of systems to acknowledge a customer...like dropping in information within the letter that is relevant'. (DM agency)

'That it recognises that they are a loyal customer and demonstrates that we, as a company, or the brand, knows who they are and their importance.' (brand-building judge)

Confirming Tapp's finding in the literature review, ${ }^{41}$ direct mail

'you are actually adding value for a select and identifiable group of individuals' (DM agency)

Another example of 'building the private face of brand' (DM agency) was the limited first edition of the Ford $\mathrm{Ka}$, which was launched through direct marketing in Sweden by offering higher specifications and features to an exclusive target group.

Fragmentation of postmodern consumers into multiple selves or roles ${ }^{42}$ is seen by one interviewee as making segmentation more difficult

'because you have many more pockets of consumers. In the old days it was all very simple because everybody was ABC1, aged between 18-55'. (DM agency)
On the positive side, tailoring the imagery, using new digital print techniques, was found to give an uplift in response:

'We produced four different laserings for one brand. It did work: it did uplift response. Tailoring the imagery as well as the text worked, against not tailoring it'. (DM agency)

In terms of building loyalty or brand commitment:

'Brand awareness is not particularly important, I don't think. It's brand experience, interacting with the brand [that counts]:... on the 'phone...p product statement... It goes well beyond advertising.' (DM agency)

'Much more meaningful to financial services than saying "Do you recognise this logo?" You should be saying: "what happens when people start dealing with the brand?" It enables financial services to build a brand through experience rather than through messages.' (DM agency)

But one DM agency talked of shortterm targets in financial services, as a 
result of fears of mergers, meaning that clients

'are not interested in a particular programme to try to nurture the customers that will take five years to come to fruition'

because they have problems with the board and shareholders.

Service expectations of brands, meanwhile, are perceived by those interviewed to have increased as a result of direct activity:

'People's experience of brand these days isn't just what they see through the TV, like it was in the old days of Persil. It's now their experience of brand as they live it...use it...ring it up...speak to it... and they expect this and that service and that will affect how brand is perceived ...so you need to make sure that your direct marketing, your fulfilment and your phone operators are all working together because people are living the brand through direct marketing, rather than just accepting it.' (DM agency)

Practical and training implications for managing the brand hostess direct marketing role at call-centres are detailed in Stevens. ${ }^{43}$

\section{DM's interactive, researcher role}

By using DM interactively to find out from consumer 'partners', not only how to improve the relevance of mailings but also how to add brand value, the brand researcher role in DM can give customers the emotional signal that the brand is listening to them:

'One of the things you can create through two-way communication is a learning relationship.... actually progressing individuals in the form of a stream. That is actually the root means of achieving emotional loyalty. The feeling that this company has listened to me and has tailored its service accordingly as a result. I am then loath to defect and start the process all over again with a stranger'. (DM agency)

Treating data with caution and respecting the level of intimacy required by the customer, which might vary depending on product class and category, is clearly felt to be critically important by direct marketers.

'I think there is a limit to how much interaction people want with a business...sending people questionnaires; "Do you want this?" "Do you want that?". I don't think it's something you can make central to your strategy, but there can be times when it's appropriate, with careful thought.' (brand-building judge)

Interviewees' views are summarised into the four roles mapped in Figure 1. Figure 1 divides media choice into mass media versus two-way communications. The greater the brand's reliance on two-way communications, such as DM, the greater the 
Figure 1: Perceptual map of DM brand roles

\section{functional/ experiential}

\section{Sales Assistant}

- There must be some brand presence first, so that at least people are familiar with who you are when your mail hits their doormat'

- 'Off-brand mailings do not pull as much response'

- 'Something can and should be done for brand at the same time as getting a response'

\section{Brand Hostess}

'Pleasant brand experience, not just awareness, is what counts'

'If you recognise who I am, you are more likely to sell me more' 'Brand loyalty depends on how you are treated as an individual and on sensitivity to your needs'

- $\quad$ 'Direct marketing can be very useful in selecting discrete groups of people and giving them preferential treatment'

mass

media

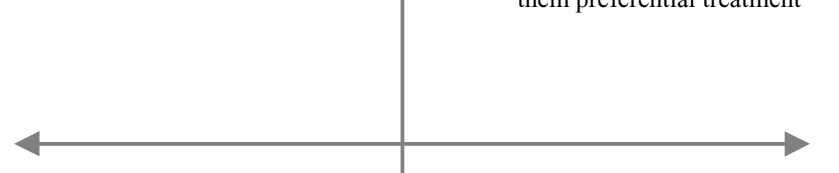

two

\section{way}

comms

\section{Brand Ambassador}

- 'DM also needs to bear allegiance to the values of the brand for which it is working

- Its job is to reinforce or to refresh the brand, but not at the expense of response'

'Should we also measure how DM adds to the brand experience or to the whole brand values?'

\section{Brand Researcher}

- Although he or she might be a loyal customer, you should always be looking to understand if there are further needs that you are not satisfying'

BUT

- 'There is a limit to the amount of interaction people want with a business'

\section{representational/ relational}

need to increase relevant differentiation in the sales assistant and brand ambassador roles, by developing the brand hostess and brand researcher roles. Figure 1 also divides the brand into 'functional' versus 'representational and relational' dimensions. While the brand ambassador role contributes mainly to representational dimensions of the brand (and can be executed via mass media), the brand researcher role is interactive and is crucial to improving the brand's relational dimensions, for whose experiential processes (ie consumer enjoyment) and functional aspects (eg acknowledgment systems) the brand hostess role is responsible. 


\section{DISCUSSION AND MANAGERIAL IMPLICATIONS}

\section{DM should be a brand-building tool}

Three strong drivers for a more strategic use of DM were found as a result of the paper's first aim. The second aim of this paper was to assess whether direct marketing is, or should be, a brand-building tool. As indicated by the literature, ${ }^{44}$ there was little support for using DM primarily as a brand-building tool, nor for using direct marketing to launch brands.

'I think it's a lot harder from a standing start; it would be a lot harder for direct response to build a brand than it would be for the branded above-the-line advertising in tandem with the direct campaign to do the job.' (DM agency)

This research paper finds, however, that most, though not all, interviewees agree that brand has a role to play in DM, if only to trigger sales if brand identity is clear, differentiated and consistent over time; or simply to reinforce the brand positioning and values established elsewhere in the marketing mix. Even these roles imply that integrating brand with customer management is needed, as has been indicated in Stone and Gamble $;^{45}$ branding being too often seen as 'a bolt-on', and even unimportant in DM, especially by senior management. Showing this to be shortsighted, DM agencies who have carried out brand research, by contrast, report uplifts in response when mailings are 'on-brand' and also a strong but hidden attitudinal impact on brand perceptions in direct mail recipients, whether they respond or not.

Awards for brand building in direct marketing, it was felt by some, should focus less on one individual campaign to improve brand consistency and long-term thinking.

More work of a brand-strategic nature was discussed than anticipated from the literature, which tends to be critical of brand building in DM. ${ }^{46,47}$ A further example from the financial services sector of focus group DM brand research, was named during the interviews to add to the literature's examples of First Direct ${ }^{48}$ and AA. ${ }^{49}$ Evidence of companies, chiefly from sectors other than financial services, setting objectives for DM brand building (as advocated by Agres and Dubitsky ${ }^{50}$ and carrying out focus group, 'on-brand' committees and panel or tracking research included companies from the following sectors: telecommunications; fmcg; supermarkets; automotive manufacturers; and High Street retailers. Continued tracking of DM for brand issues, however, was considered unusual because of the high perceived costs involved.

\section{The different roles DM plays in branding or brand building}

The third aim of the paper was to shed light on the role of branding in financial services direct marketing. Four brand-building roles for direct marketing have emerged: sales assistant, brand ambassador, brand hostess 
Figure 2: Four brand building roles for direct marketing

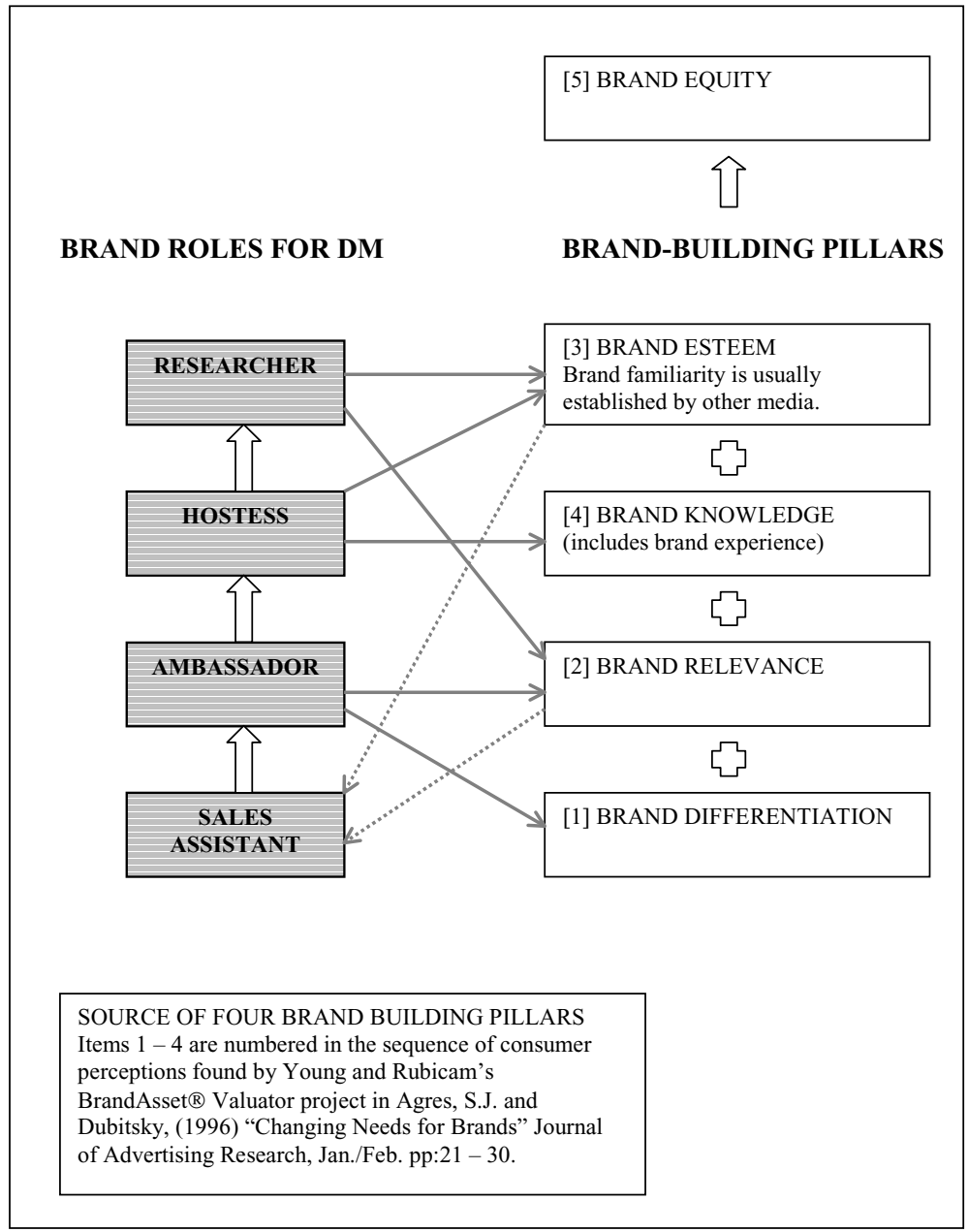

and brand researcher, as outlined in Figure 1. The proposed DM brand roles could be analysed to assess how far a particular brand-building pillar could be strengthened via direct marketing. This could help in setting DM objectives, other than sales tar- gets, as recommended by Agres and Dubitsy. ${ }^{51}$ Figure 2 shows how these roles can be aligned with three of the brand-building pillars identified in Agres and Dubitsky, except for 'esteem', and how, by incorporating DM's brand roles into strategic plan- 
ning, they could contribute to building brand equity.

It is not proposed that more than one of these brand-building roles should be incorporated into any single direct mail piece, but it is proposed that DM campaigns that neglect them may risk:

- producing direct mail that is either 'off-brand' and ignored; or 'anti brand', ie conflicting with the brand values established elsewhere, producing incoherent communications and probably dissonance in the consumer

- underperformance in terms of response rates, sales, strengthening the customer-brand bond to prevent switching, cross-sales and encouraging brand advocacy.

Interviewees confirmed the lack of investment in customer information, other than financial data, posited by Fletcher. ${ }^{52}$ This means that any potential in the direct media for the brand hostess role tends to be underutilised.

Although many interviewees stressed the importance of taking care with customers' experience of brands, especially in services, few had the 'Dionysian' spirit of experiential branding found in Schmitt, ${ }^{53}$ and demonstrated in an interesting, eyecatching way by the Casa Buitoni Club. ${ }^{54}$ This suggests that direct marketing, is still waking up to its creative and emotional possibilities. It could proactively supply customers with experiential, ${ }^{55}$ rather than merely visual or verbal, branding.

Pearson's suggestions for 'activating the customer' such as providing non-selling advice or literature, briefly outlined in the literature review, were not mentioned much as part of the direct marketing arsenal. ${ }^{56}$ DM agencies felt almost unanimously that clients, especially those in financial services with their merger fears, would not invest in long-term brand-building activity without a selling motive. It is difficult to assess the scale of more experimental brand-building work, such as an example linked to the building of a retail customer database; this type of information was restricted because it was deemed commercially sensitive. There was little mention of processing customers through stages of a brand loyalty ladder ${ }^{5-59}$ though it may be that client's loyalty-building activity is being carried out elsewhere or inhouse. Interviewees felt that client organisations are 'not integrated'. Organisational structure needs to be less divisive so that building loyalty is not simply compartmentalised into 'the loyalty scheme'. A more 'horizontal ownership' of 'the brand(s)', 'acquisition' and 'retention' is required for strategic brand building now that multiple media and interactive distribution channels are available to consumers.

\section{Recommendations for further research}

The authors found little in the way of published case studies of brand building through DM or multiple media. 
Publishing such cases, as the IPA does for advertising, may encourage marketers to use DM more effectively for brand building.

A client marketer perspective and the perspective of brand consultants might usefully be sought and compared to achieve a triangulation of views on how and to what extent direct marketing does and should fulfil a creative and a 'brand experience' role within brand building and maintenance.

A quarter of UK terrestrial television advertisements carry direct response numbers $^{60}$ and the advent of set-top boxes promises more interactive communications. This study set out to look at branding chiefly in direct mail, but it might now be useful to examine the proposed four brand roles for DM found here (Figure 1) in the context of other new media.

\section{CONCLUSIONS}

In some DM agencies with an account planning heritage, brand building has played a role in direct marketing for the past five to ten years. The three main drivers for the move from tactical to more creative, brand-strategic direct marketing are summarised as economics, DM market factors and technological progress.

If sufficient investment is made in information infrastructures to allow for meaningful dialogue with existing customers, direct marketing's strategic role in brand building could be more important for retention than for acquisition. Direct mail is not seen as the ideal medium for building a brand from scratch.

Setting objectives for each of the DM brand roles, sales assistant, brand ambassador, brand hostess and brand researcher will result in using direct marketing to its full potential with regard to brand building.

Lack of senior management involvement in DM campaigns, the perception of DM as a 'junior partner in marketing' (brand-building judge) and the lack of an integrated structure for brand management, all contribute to leaving brand out in the cold. In many cases direct mail is still treated as little more than a semi-targeted, mass medium: a press advertisement folded into an envelope, underexploiting its role in improving customer 'brand experience', especially for the service brand; and its potential for two-way dialogue and adding brand value.

\section{ACKNOWLEDGMENTS}

The participants in this study are thanked for giving their time. This research was sponsored by the Royal Mail. Grateful acknowledgments are also due to the UK's DMA West for their coordination role in the research and funding; to Stella Warren, at Bristol Business School, for her transcription of interview tape recordings; and to the IDM information centre for their assistance.

\section{REFERENCES}

1 DMIS (1999) 'Key Mail Statistics', Direct Mail Information Service, London, UK. 
2 Hartley, B. and Pickton, D. (1999) 'Integrated marketing communications requires a new way of thinking', Journal of Marketing Communications, Vol. 5, pp. 97-106.

3 Kotler, P. (1996) Chartered Institute of Marketing Annual Lecture.

4 de Chernatony, L. and McDonald, M. (1998) 'Creating powerful brands in consumer, service and industrial markets', published in association with the Chartered Institute of Marketing by Butterworth Heinemann, 2nd edition, Oxford, p. 20.

5 Agres, S. J. and Dubitsky, T. M. (1996) 'Changing needs for brands', Journal of Advertising Research, January/February, pp. 21-30.

6 Joachimsthaler, E. and Aaker, D. A. (1997) 'Building brands without mass media', Harvard Business Review, January-February, pp. 39-50.

7 Howard, D. (1998) 'Creating cohesion in brand development', Admap, July/August, pp. 12-14.

8 Douglass, D. and May, D. (1999) 'It takes two to tango', Admap, June, pp. 21-23.

9 Joachimsthaler and Aaker (1997) op. cit.

10 Douglass and May (1999) op. cit.

11 Fletcher, K. (1999) 'Inside the brand', Marketing Direct, June, pp. 57-58.

12 Reed, D. (1998) 'Dial challenge', Marketing Week, 6 August, pp. 35-38.

13 Hallberg, G. (1996) 'All consumers are not created equal', John Wiley \& Sons, New York and London.

14 Hallberg, G. (1999) 'The future of differential marketing, Journal of Targeting, Measurement and Analysis for
Marketing, Vol. 7, No. 4, pp. 325334.

15 Pearson, S. (1996) 'Building brands directly: Creating business value from customer relationships', Macmillan Press Ltd, Hampshire and London.

16 In Fletcher (1999) op. cit.

17 Pearson (1996) op. cit., pp. 153, 340 and 166.

18 Gardiner, P. and Quinton, S. (1998) 'Building brands using direct marketing - a case study', Marketing Intelligence and Planning, Vol. 16, No. 1, pp. 611.

19 McCorkell, G. (1997) 'Direct and database marketing', Kogan Page, London.

20 Kashani, K. (1995) 'A new future for brands', Financial Times, supplement on management, 3 November.

21 Stone, M. and Gamble, P. R. (1999) 'Managing financial services customers through the mail: Part 2', Journal of Financial Services Marketing, Vol. 3, No. 2, pp. 117-136.

22 Tapp, A. (1998) 'Principles of direct \& database marketing', Financial Times Publishing, London.

23 Patterson, M. (1998) 'Direct marketing in post-modernity: Neo-tribes and direct communications', Marketing Intelligence \& Planning, Vol. 16, No. 1, pp. 68-74.

24 de Chernatony and McDonald (1998) op. cit.

25 Rapp, S. and Collins, L. (1994) 'Beyond maxi-marketing', McGrawHill.

26 Kapferer, J-N. (1997) 'Strategic brand management: Creating and sustaining brand equity long term', Second Edi- 
tion, published by Kogan Page Ltd, pp. 165-166.

27 Pearson (1996) op. cit., p. 340.

28 ibid.

29 Hussey, J. and Hussey, R. (1997) 'Business Research', Macmillan Press Ltd, Hampshire, p. 158.

30 Lee, R. M. (1993) 'Doing research on sensitive topics', Sage, London.

31 Marketing (1997) 'Direct marketing league tables, direct marketing agencies (league table by turnover)', 6 March, pp. IX-X.

32 ibid.

33 Huberman, A. M. and Miles, M. B. (1994) 'Data management and analysis methods', in Denzin, N. K. and Lincoln, Y. S. (eds) 'Handbook of qualitative research, pp. 428-444, Sage, Thousand Oaks, CA.

34 See also Wolcott, H. (1994) 'Transforming qualitative data: Description, analysis and interpretation', Sage, Thousand Oaks, CA.

35 DMIS (1998) 'Insurance sector intelligence report', Direct Mail Information Service, London.

36 Howcroft, J. B. and Wells, N. H. (1989) 'Customer satisfaction in retail banking', Research Paper No. 63, Loughborough University.

37 Reid, J. (1995) 'Branding in financial services. Public knowledge about financial services is poor. What does this suggest about advertising and branding strategies?', Admap, May, pp. 26-28.

38 Timewell, S. (1996) 'Shopping for Money', The Banker, Vol. 146, August, p. 18.

39 Hoskin, F. and Beaver, J. (1997) 'An examination of loyalty in financial services', MRS Conference Papers.

40 Patterson (1998) op. cit.

41 Tapp (1997) op. cit.

42 Firat, A. F. and Shultz, C. J. II (1997) 'From segmentation to fragmentation: Markets and marketing strategy in the postmodern era', European Journal of Marketing, Vol. 31, No. 3/4, pp. 183207.

43 Stevens, M. (1998) 'Brand values down the line or down the drain?', Marketing Direct, October.

44 Joachimsthaler and Aaker (1997) op. cit.

45 Stone and Gamble (1999) op. cit.

46 Joachimsthaler and Aaker (1997) op. cit.

47 Fletcher (1999) op. cit.

48 Stevens (1998) op. cit.

49 Reed (1998) op. cit.

50 Agres and Dubitsky (1996) op. cit.

51 ibid.

52 Fletcher (1999) op. cit.

53 Schmitt, B. (1999) 'Experiential marketing', Journal of Marketing Management, Vol. 15, pp. 53-67.

54 Joachimsthaler and Aaker (1997) op. cit.

55 See also Macrae, C. (1999) 'Mini cases on brand reality', Journal of Marketing Management, Vol. 15, pp. 107-116.

56 Pearson (1996) op. cit.

57 ibid.

58 Light, L. (1997) 'Brand loyalty management the basis for enduring profitable growth', Direct Marketing, March, pp. 36-43.

59 Light, L. (1998) 'Brand loyalty management - the new marketing basic', Admap, May, pp. 28-29.

60 Reed (1998) op. cit. 